\title{
Hymenoptera stings: a study of clinical profile, complica- tion and outcome from a teaching hospital of central Nepal
}

\author{
Ghimire M, ${ }^{1}$ Pahari B, ${ }^{1}$ Paudel $N,{ }^{1}$ Das $G,{ }^{2}$ Sharma SK, ${ }^{3}$ Das GC ${ }^{4}$
}

${ }^{1}$ DM Nephrology Resident, ${ }^{2}$ Lecturer Department of Nephrology, ${ }^{3}$ Department of Cardiology, ${ }^{4}$ Professor and HOD, Department of Nephrology, College of Medical Sciences Teaching Hospital, Bharatpur, Nepal

\section{ABSTRACT}

\section{Background}

Hymenoptera sting is a common health hazard in the tropics. Wasp and Bee stings can produce symptoms ranging from local allergic reactions to serious complications including anaphylaxis and multiple organ dysfunction syndromes.

\section{Objective}

To evaluate the clinical profile, management and early outcome of patients with gallbladder cancer.

\section{Methods}

We prospectively analyzed all the consecutive patients with Hymenopterid sting (Wasp and Bee stings), who were admitted in Nephrology Unit in college of Medical Sciences Teaching hospital over a period of two year; from June 2010 to May 2012. Data including demographic profile, clinical profile, complications and outcomes associated with the Hymenopterid stings were entered in a designated profroma and were analyzed.

\section{Results}

A total of 15 cases with Hymenopterid stings (Wasp and Bee stings) were analyzed. Majority of the cases were females $(n=8)$. The male to female ratio was 0.88 . The mean age of the case was $37.1 \pm 17.38$ years. Most of the cases $(n=11)$ were younger subjects d"45 years and majority of them felt in the age group of 21-30 years; $(n=4)$. Mean number of stings (Wasp or Bee stings), were $46 \pm 18.4(12-74)$ and the mean time to reach the hospital from the bite time was $78.23 \pm 82.24$ hours ( 30 minutes- 13 days). Black Wasps were the commonest species to inflict the stings in $(n=10)$ cases and Bees in $(n=5)$ cases. The Hymenoptera stings were observed more frequently in the month of July to September in $(n=8)$. The commonest site of bite was head and face seen in $(n=11)$ cases. Among the clinical presentations the commonest clinical presentation was local burning pain and pruritus which was present in all the cases $(n=15)$ followed by nausea $(n=10)$. The commonest clinical sign was bipedal edema which was seen in $(n=7)$ cases. Low $\mathrm{Hb}$ (defined as $\mathrm{Hb}<10 \mathrm{gm} / \mathrm{dl}$ ) was seen in $(n=5)$ cases of Hymenopterid stings. Low platelet (defined as Platelet $<100 \times 10^{9} / L$ ) was documented in $(n=10)$ cases. Serum creatinine $>1.5 \mathrm{mg} / \mathrm{dl}$ was seen in $(n=7)$ cases. Low serum albumin (defined as Serum Albumin $(<3.5 \mathrm{gm} / \mathrm{dl})$ was seen in $(n=6)$ cases. Among the complications, the most common complication was Hepatitis which was seen in $(n=9)$ cases, followed by Acute Kidney Injury. There was no mortality associated with Hymenopterid stings in our study. However 1 patient left against medical advice.

\section{Conclusion}

Black Wasps were the commonest species to inflict the stings in $(n=10)$ cases. The most common complication of Hymenoptera sting was Hepatitis, which was seen in $(n=9)$ of cases, followed by Acute Kidney Injury. Majority of complications were seen in Wasp stings which caused significant morbidity. No mortality was observed in our study except one case; that left hospital against medical advice.

Key Words: Hymeneptora stings, complication,outcome

Correspondence: Dr. Madhav Ghimire

E-mail: madhavghimirenp@yahoo.com 
Journal of College of Medical Sciences-Nepal, 2013, Vol-9, No-3,

\section{INTRODUCTION}

The medically important species of Hymenoptera order are the Apoidea (Honeybees, Bumble bees, Africanized bees), Vespoidea (wasps, hornets, and yellow jackets), and Formicidae (ants). Hymenoptera are social creatures. They typically sting following provocation to protect themselves from their enemies. The potentially lethal number of Hymenoptera stings that has been estimated to be lethal is 500 stings, and the death is probably due to a direct systemic effect of the venom. ${ }^{1}$ Systemic toxic effects of bee venom are generally seen in patients with more than 50 stings. ${ }^{2}$ However, the anaphylactic reactions to Hymenoptera stings are not dose dependent. ${ }^{3}$ The majority of Hymenopteran stings are self-limiting events, which resolve in a few hours without treatment. However, some of the serious reactions of Hymenoptera stings due to multiple stings can rarely cause angioedema, hemolysis, acute renal failure, rhabdomyolysis, neuritis, Vasculitis, encephalopathy and serum sickness. ${ }^{4,5}$

\section{METHODS}

We prospectively analyzed 15 consecutive cases of Hymenopterid stings (Wasp and Bee stings), who were admitted in Nephrology Unit in college of Medical Sciences Teaching hospital over a period of two year; from June 2010 to May 2012. Data including demographic profile, clinical profile, complications and outcomes associated with the Hymenopterid stings were entered in a designated profroma and were analyzed using Microsoft Excel 2010. The diagnosis of Hymenopterid sting (Wasp and Bee sting) was based on clinical history and physical findings. Investigations were performed to look for the evidence of complications in the form of multi organ dysfunction syndrome (MODS) e.g. hemolysis, liver injury, acute renal failure, rhabdomyolysis, coagulopathy, pulmonary edema, secondary hypertension and seizure. The patients were followed up during the hospital stay to look for development of new complications and to document the outcome at the time of discharge.

\section{RESULTS}

We analyzed the 15 consecutive cases of Hymenopterid stings (Wasp and Bee stings). The mean age of the case was 37.1 17 .38years. Majority of the cases were female $(n=8)$. The male to female ratio was 0.88 . The mean number of stings (wasp or bee stings), were $46 \pm 18.4$ stings (12-74) and the mean time to reach the hospital from the bite time was $78.23 \pm 82.24$ hours (30 minutes-13 days). In terms of species, Black wasps were the commonest species to inflict the sting in $(n=10)$ cases and Bee in $(n=5)$ cases. The Hymenoptera stings were observed more frequently in the month of July to September in $(n=8)$ cases followed by October to December in $(n=5)$ cases.(Table1) 
Ghimire M. et al. hymenoptera stings.

Table 1. Demographic Profile

\begin{tabular}{|c|c|c|c|}
\hline Age & Mean age $37.1 \pm 17.38$ & & \\
\hline Sex & Male $(n=7)$ & Female $(n=8)$ & \\
\hline Male: Female Ratio & 0.88 & & \\
\hline Mean Hospital stay in days & $6.73 \pm 3.84$ days & & \\
\hline Average number of Sting & $46 \pm 18.4$ Stings & & \\
\hline Duration of bite time to & $78.23 \pm 82.24$ hours & & \\
\hline Emergency visit time & (30 minutes-13 days). & & \\
\hline Species of Hymenoptera & & & \\
\hline Black Wasp & $(\mathrm{n}=10)$ & & \\
\hline Bee Sting & $(n=5)$ & & \\
\hline Month of Sting & Total Number & Wasp & Bee \\
\hline July to September & $(n=8)$ & $(n=6)$ & $(n=2)$ \\
\hline October to December & $(n=5)$ & $(n=3)$ & $(n=2)$ \\
\hline January to February & $(n=2)$ & $(n=1)$ & $(\mathrm{n}=1)$ \\
\hline
\end{tabular}

Among the clinical presentation the commonest clinical presentation was local burning pain and pruritus which was present in all the cases $(n=15)$ followed by nausea $(n=10)$ and then vomiting $(n=8)$. Oliguria, cola colored urine, body swelling, dyspnea and muscle pain was seen in $(n=7)$ cases each( Table 2$)$.

Table 2. Clinical Presentations (Symptoms)

$\begin{array}{lccc}\text { Symptoms } & \text { Total Number } & \text { Wasp } & \text { Bee } \\ \text { Burning pain/Pruritus } & (\mathrm{n}=15) & (\mathrm{n}=10) & (\mathrm{n}=5) \\ \text { Nausea } & (\mathrm{n}=10) & (\mathrm{n}=6) & (\mathrm{n}=4) \\ \text { Vomiting } & (\mathrm{n}=8) & (\mathrm{n}=6) & (\mathrm{n}=2) \\ \text { Oliguria } & (\mathrm{n}=7) & (\mathrm{n}=7) & (\mathrm{n}=0) \\ \text { Cola Colored Urine } & (\mathrm{n}=7) & (\mathrm{n}=7) & (\mathrm{n}=0) \\ \text { Body swelling } & (\mathrm{n}=7) & (\mathrm{n}=7) & (\mathrm{n}=0) \\ \text { Dyspnea } & (\mathrm{n}=7) & (\mathrm{n}=7) & (\mathrm{n}=0) \\ \text { Muscle Pain } & (\mathrm{n}=7) & (\mathrm{n}=5) & (\mathrm{n}=2) \\ \text { Loss of Consciousness } & (\mathrm{n}=3) & (\mathrm{n}=2) & (\mathrm{n}=1) \\ \text { Gumbleeding } & (\mathrm{n}=1) & (\mathrm{n}=1) & (\mathrm{n}=0)\end{array}$

The commonest clinical sign was bipedal edema which was seen in $(n=7)$ cases. Ascites was detected in $(n=6)$ cases ( Table 3).

Table 3 Clinical Presentations (Signs)

$\begin{array}{lccc}\text { Signs } & \text { Total Number } & \text { Wasp } & \text { Bee } \\ \text { Pallor } & (\mathrm{n}=5) & (\mathrm{n}=5) & (\mathrm{n}=0) \\ \text { Bipedal edema } & (\mathrm{n}=7) & (\mathrm{n}=7) & (\mathrm{n}=0) \\ \text { Icterus } & (\mathrm{n}=1) & (\mathrm{n}=1) & (\mathrm{n}=0) \\ \text { Bite site wound } & (\mathrm{n}=6) & (\mathrm{n}=6) & (\mathrm{n}=0) \\ \text { Ascites } & (\mathrm{n}=6) & (\mathrm{n}=6) & (\mathrm{n}=0)\end{array}$


Journal of College of Medical Sciences-Nepal, 2013, Vol-9, No-3,

The commonest site of bite was head and face which was seen in $(\mathrm{n}=11)$ cases.

\section{Table 4. Laboratory Parameters}

\section{Laboratory Parameters}

Hemoglobin $(<10 \mathrm{gm} / \mathrm{dl})$

Platelet $<100 \times 10^{9} / \mathrm{L}$

Serum creatinine e" $1.5 \mathrm{mg} / \mathrm{dl}$

Total Creatine Kinase(>300 IU/L)

$\mathrm{LDH}(>230 \mathrm{IU} / \mathrm{L})$

SerumAlbumin $(<3.5 \mathrm{gm} / \mathrm{dl})$

Serum Uric Acid ( $>7 \mathrm{mg} / \mathrm{dl})$

Total Number
$\begin{aligned} & (\mathrm{n}=5) \\ & (\mathrm{n}=1) \\ & (\mathrm{n}=7) \\ & (\mathrm{n}=6) \\ & (\mathrm{n}=7) \\ & (\mathrm{n}=6) \\ & (\mathrm{n}=5)\end{aligned}$

Among the complications, the most common complication was Hepatitis seen in $(n=9)$ cases, followed by AKI. Rhabdomyolysis and myositis were seen in $(n=7)$ cases each. Seizure, coagulopathy and pulmonary edema were observed in $(n=1)$ cases, each. All the seven patients who developed AKI underwent hemodialysis ( Table 5).

\section{Table 5. Complications}

$\begin{array}{llll} & & \text { Wasp } & \text { Bee } \\ \text { Hepatitis } & (\mathrm{n}=9) & (\mathrm{n}=7) & (\mathrm{n}=2) \\ \text { AKI } & (\mathrm{n}=7) & (\mathrm{n}=7) & (\mathrm{n}=0) \\ \text { Pulmonary edema } & (\mathrm{n}=1) & (\mathrm{n}=1) & (\mathrm{n}=0) \\ \text { HTN } & (\mathrm{n}=2) & (\mathrm{n}=2) & (\mathrm{n}=0) \\ \text { Hemolysis } & (\mathrm{n}=5) & (\mathrm{n}=5) & (\mathrm{n}=0) \\ \text { Myositis/Rhabdomyolysis } & (\mathrm{n}=7) & (\mathrm{n}=5) & (\mathrm{n}=2) \\ \text { Coagulopathy } & (\mathrm{n}=1) & (\mathrm{n}=1) & (\mathrm{n}=0) \\ \text { Seizure } & (\mathrm{n}=1) & (\mathrm{n}=1) & (\mathrm{n}=0)\end{array}$

Table 6. Outcome

$\begin{array}{lccc} & & \text { Wasp } & \text { Bee } \\ \text { Overall Mortality } & \text { None } & (\mathrm{n}=0) & (\mathrm{n}=0) \\ \text { LAMA(Left against Medical Advise) } & (\mathrm{n}=1) & (\mathrm{n}=1) & (\mathrm{n}=0)\end{array}$

There were no in hospital mortality events associated with Hymenopterid stings. However 1 patient left against medical advice (LAMA). 
Ghimire M. et al. hymenoptera stings.

\section{DISCUSSION}

\section{Demographic Profile}

The mean age of the case was $37.1 \pm 17.38$ years and the majority of the cases were younger subjects $\mathrm{d}$ "45 years; $(n=11)$ and most of them fell in the young age group of $21-40$ years; $(n=7)$. People in this age group are active and they frequently go out for work, hence are at risk of stings. The majority of the cases were females $(n=8)$ and the male to female ratio was 0.88 . The female preponderance seen in our study may be because of two reasons. One, in our community mostly females go to jungle for grass cutting and woods collection where they incidentally happen to disturb the insect hives. Second, females usually wear colorful dresses that often attract the Bees and Wasps. Hence females are at risk of stings. In temperate climates, stings occur during late summer and in early fall, when large numbers of hungry wasp are attracted to the food of humans eating outdoors ${ }^{6}$ but their numbers peak in August. ${ }^{7}$ Similar to the study done by Bischof, ${ }^{7}$ Our study also showed the higher number of stings during months from July to September.

\section{Species Identification}

In most of the conditions, it is difficult to identify the culprit insect that inflicted the stings and similar scenario was also present in our study. Physician need to use secondary evidences like the presence of the stinger; most common with honeybees and the presence of pustule found after imported fire ant stings to identify the species. Our cases were just able to tell whether insects were Bees or Black wasps.

If a patient could identify the insect that caused the sting or could at least bring the insect to the hospital along with them, this could be helpful in diagnosis, prognosis and treatment.

\section{Number of Stings}

The average number of sting was $46 \pm 18.4$, with the maximum number of stings documented in our cases were 74 (Bee stings) and the minimum were 12 stings (Wasps stings). The minimum Bee stings required to develop systemic complication were 58 , which was similar to the number documented in the literature. ${ }^{3,8}$

\section{Clinical presentation}

In a study done by Diaz-Sanchez et al, ${ }^{1}$ the clinical presentations of honey bees stings were generalized edema, arterial hypotension, hemolysis, rhabdomyolysis and acute renal failure. Studies regarding the clinical profile in Hymenopterid stings are scarce in the literature.

The most frequent clinical symptoms seen in our study were local burning pain and pruritus followed by nausea and vomiting .Other symptoms, in the form of oliguria, cola colored urine, body swelling, dyspnea and muscle pain were seen in approximately half of the cases .Similarly, the common clinical findings in our study were bipedal edema, ascites and pallor. 
Journal of College of Medical Sciences-Nepal, 2013, Vol-9, No-3,

\section{Complications}

A minimum of 20 wasp stings were required for the development of major complications like hepatitis or AKI. In our study a minimum of 12 wasp stings were sufficient to produce the major complication. Similarly a minimum of $>50$ bee stings were required for the development of major complications ${ }^{3,8}$, which was similar to our study, where the minimum Bee stings required to develop systemic complication were 58 in number.

\section{Hepatic dysfunction}

Wasp sting induced hepatic dysfunction is rarely reported in literature and its pathogenesis is also not clear. In a review, ${ }^{9}$ abnormal liver function tests were observed 6 out of 7 evaluated cases.

The most common complication in our study was Hepatitis. Majority of the hepatic dysfunction were due to Wasp stings in ( $\mathrm{n}=8)$ vs. $(\mathrm{n}=1)$ Bee stings.

\section{AKI}

Complication of hymenopteran stings in the form of AKI was seen in $(n=7)$ cases and all the renal injuries were due to Wasp stings in $(n=7)$ cases vs. $(n=0)$ Bee stings. All the subjects who developed AKI required hemodialysis as renal support. Out of 7 patients with rhabdomyolysis, 5 patients developed AKI. The mechanism of AKI in Hymenoptera stings is multifactorial.

\section{Myositis/Rhabdomyolysis}

The exact mechanism of rhabdomyolysis is not known but a direct toxic effect of venom on muscle is believed to be the main cause. ${ }^{10}$ Clinically significant muscle pain when accompanied by high CK level were labeled as having rhabdomyolysis, which was present in $(n=7)$ cases. The tests for CK level were not performed daily, so we could not observe the progression of serum $\mathrm{CK}$ level. Majority of the myositis/rhabdomyolysis were due to Wasp stings in ( $n=5)$ vs. $(n=2)$ Bee stings.

\section{Hemolysis}

In a review of 12 cases of wasp stings, hemolysis were observed in 10 out of 10 cases. $^{9}$

In the present study, hemolysis was observed in $(n=5)$ cases and all the cases were due to Wasp stings in $(n=5)$ vs. $(n=0)$ Bee stings.

\section{Coagulopathy}

In a study done by Habermanne, thrombocytopenia was an uncommon complication and when it occurred, it was likely to be due to a direct toxic effect on platelets. ${ }^{11}$ In our study, thrombocytopenia was seen in only one case $(n=1)$ and all it was due to Wasp stings.

\section{MODS}

MODS has been usually reported after multiple wasp stings. ${ }^{12-14}$ However, in a study done by Sharmila et al, MODS and death was observed even after a single wasp sting in a 12-year-old boy. ${ }^{15}$ In our study MODS defined as involvement of 2 or more organ was seen in $(n=7)$ cases and all the cases were due to Wasp stings.

\section{Duration of Hospital stay}

The mean hospital stay of our study was $6.73 \pm 3.84$ days. It was also seen in our study that patients who had less numbers of hymenoptera stings had shorter duration of hospital stay and they had less severe complications which was similar to a previous report. ${ }^{16}$

\section{Outcome/Mortality}

The mortality due to massive insect stings have been reported and estimated to range from 15 to 25 percent. ${ }^{3,17-19}$ Death have been documented to occur 
Ghimire M. et al. hymenoptera stings.

when the Wasp stings were in the range of 20-200 and may occur within 4 hours to 9 days of stings. ${ }^{20}$ However in our study no immediate in hospital mortality was documented at the time of discharge except one case that left hospital against medical advice.

\section{CONCLUSION}

Black wasps were the commonest species to inflict the stings. Clinical spectrum of Hymenopteran stings ranges from mild self-limiting events to a serious life threatening multiple organ dysfunctions syndrome. However, the prognosis is good with satisfactory recovery even from MODS. The most common complication was Hepatitis, followed by AKI. Majority of complications were seen in Wasp stings which causes significant morbidity. No mortality was observed in the study except one case; that left hospital against medical advice. Early recognition of complication is crucial to the successful management of these patients.

\section{ACKNOWLEDGEMENTS}

Part of this work has been accepted as abstract at the World Congress of Nephrology 2013 to be held between 31 May and 4 June 2013 in Hong Kong. We would like to thank all the Patients and Nursing staffs of Nephrology ward and Hemodialysis Unit, who were directly and indirectly involved in the study.

\section{REFERENCES}

1. Diaz CL, Lifshitz GA, Ignacio IG, et al. A survival after massive (>2000) Africanized honeybees stings. Arch. Intern Med 1998; 158: 925-27.
2. Thiruventhiran T, Goh BL, Leong CL, et al. Acute renal failure following multiple wasp stings. Nephrol. Dial. Transplant 1999; 14: 214-17.

3. Fitzgerald KT, Flood AA. Hymenoptera stings. Clin Tech Small Anim Pract. 2006; 21: 194204.

4. Light WC, Reisman RE, Shimizu M, et al. Unusual reactions following insect stings: clinical features and immunologic analysis. J Allergy Clin Immunol 1977; 59: 391-97.

5. Abuelo JG. Renal failure caused by chemicals, foods, plants, animal venoms and misuse of drugs. An Overview. Arch Intern Med 1990; 150:505-10.

6. Edwards R. Social Wasps: their Biology and Control. East Grinstead, Rentokil Ltd, 1980.

7. Bischof RO. Seasonal incidence of insect stings: autumn 'yellow jacket delirium.' J Fam Pract 1996; 43:271-3.

8. Tunget CL, Clark RF. Invasion of the killer bees, separating facts from fiction. Post Grad Med 1993; 94: 92-102.

9. Atmaram VP, Mathew A, Kurian G, et al. Acute renal failure following multiple wasp stings. Indian J Nephrol 2005; 15: 30-2.

10. Kim YO, Yoon SA, Kim KJ, et al. Severe rhabdomyolysis and acute renal failure due to multiple wasp stings. Nephrol Dial Transplant 2003; 18: 1235.

11. Habermann E. Bee and wasp venoms. Science 1972; 177: 314-22. 
Journal of College of Medical Sciences-Nepal, 2013, Vol-9, No-3,

12. Pramanik S, Banerjee S. Wasp stings with multisystem dysfunction. Indian Pediatr. 2007; 44:788-90.

13. Ghosh JB, Roy M, Bala AK. Delayed onset interstitial nephritis following multiple wasp stings. Indian J Nephrol. 2009;19:71-3.

14. Bhatta N, Singh R, Sharma S, et al. Acute renal failure following multiple wasp stings. Pediatr Nephrol. 2005; 20:1809-10.

15. Sharmila RR, Chetan G, Narayanan P, et al. Multiple organ dysfunction syndrome following single wasp sting. Indian J Pediatr. 2007; 74: 1111-2.

16. Daher EF, Junior GBS, Bezerra GP, et al. Acute renal failure after massive honeybee stings.
Revista Instituto Medicina Tropical de Sao Paulo 2003; 45: 45-50.

17. Mejia G, Arbelaez M, Henao, JE, et al. Acute renal failure due to multiple stings by Africanized bees. Ann intern Med 1986; 104: 210-11.

18. Michener CD. The Brazilian bee problem. Ann. Rev. Ent.1975; 20: 399-416.

19. Sert M, Tetiker T, Paydas S. Rhabdomyolysis and acute renal failure due to honeybee stings as an uncommon cause. Nephron, 1993; 65: 647.

20. Vetter RS, Visscher PK, Camazine S. Mass envenomations by honey bees and wasps. West J Med 1999; 170: 223-27. 